•研究报告・

\title{
转基因玉米对田间节肢动物群落多样性的影响
}

\author{
马燕婕 ${ }^{1}$ 何浩鹏 ${ }^{1}$ 沈文静 ${ }^{2}$ 刘 标 $^{2 *}$ 薛 ${ }^{\text {伩 }}{ }^{1,2 *}$ \\ 1 (中央民族大学生命与环境科学学院, 北京 100081) \\ 2 (生态环境部南京环境科学研究所, 南京 210042)
}

\begin{abstract}
摘要: 通过对转基因耐除草剂(EPSPS)抗虫(Cry1Ab)玉米转化体“DBN9936’、受体玉米“DBN318’、常规玉米‘先玉 335 和喷施除草剂的转化体 'DBN9936”玉米田中节肢动物种类及数量的调查, 评价转基因玉米对田间节肢动物群 落多样性的影响。2015年和2017年我们采用直接观察法、陷阱调查法和剖秆法对田间节肢动物进行调查, 采用聚 类分析、物种累积曲线等方法对数据进行分析, 并比较了 4 个处理玉米田节肢动物群落的Margalef丰富度指数、 Shannon-Wiener多样性指数、Simpson多样性指数、Pielou均匀度指数、优势集中性指数和群落相似性指数的差异 及其随时间变化的规律。调查期间共记录节肢动物20目80科; 转化体玉米 'DBN9936’ (2015: $10.3 \pm 2.6$ 头, 2017: $3.3 \pm 1.7$ 头)和喷施除草剂的转化体玉米“DBN9936’ (2015: 6.0 1.5 头, 2017: $17.0 \pm 0.6$ 头)上鳞翅目昆虫的数量明显 低于受体“DBN318’ (2015: $20.0 \pm 3.2$ 头, 2017: $24.0 \pm 6.0$ 头)和“先玉335’ (2015: $21.0 \pm 8.9$ 头, 2017: $26.7 \pm 2.0$ 头); 物 种累积曲线呈典型的抛物线, 各类玉米田间总体物种丰富度差异较小; 玉米生育期节肢动物调查结果累计数量的 功能团组成及其丰富度、多样性、均匀度、优势集中性间均无明显的差异, 各类指数随时间变化的动态趋于一致, 群落间相似性程度较高。转基因玉米‘DBN9936'对鳞翅目害虫有明显的抗性, 对非靶标节肢动物无显著的影响, 对 田间节肢动物的群落多样性、均匀度、丰富度、优势集中性等没有明显的影响。
\end{abstract}

关键词: 转基因玉米; 生物多样性; 节肢动物; 多样性指数; 生物安全

\section{Effects of transgenic maize on arthropod diversity}

\author{
Yanjie $\mathrm{Ma}^{1}$, Haopeng $\mathrm{He}^{1}$, Wenjing Shen ${ }^{2}$, Biao Liu ${ }^{2 *}$, Kun Xue ${ }^{1,2^{*}}$ \\ 1 College of Life and Environmental Sciences, Minzu University of China, Beijing 100081 \\ 2 Nanjing Institute of Environmental Sciences, Ministry of Ecology and Environment, Nanjing 210042
}

\begin{abstract}
The species and numbers of arthropods in fields of transgenic herbicide-tolerant (EPSPS) and insect-resistant (Cry1Ab) maize DBN9936, receptor maize DBN318, conventional maize Xianyu 335, and spraying herbicide transformant DBN9936, were investigated to assess the effect of genetically modified maize on the arthropod communities. Direct observations, pit-fall trapping and longitudinal section methods were used to investigate the field arthropod species in 2015 and 2017. A cluster analysis and species accumulation curves, as well as the Margalef richness index, Shannon-Wiener index and Simpson index, Pielou evenness index, dominant concentration index, community similarity index, were calculated and compared. The recorded arthropod species belonged to 20 orders and 80 families. The number of Lepidopteron insects in the fields of herbicide-free transformant DBN9936 (2015: $10.3 \pm 2.6$, 2017: $3.3 \pm$ 1.7) and transformant DBN9936 spraying herbicides (2015: $6.0 \pm 1.5$, 2017: $17.0 \pm 0.6$ ) were significantly lower than the corresponding parameters of receptor DBN318 (2015: $20.0 \pm 3.2,2017$ : $24.0 \pm$ 6.0) and Xianyu 335 (2015: $21.0 \pm$ 8.9, 2017: $26.7 \pm 2.0$ ). The species accumulation curves show a typical parabola and there was little difference in the overall species richness. There were no significant differences in the total number of arthropods, functional group composition, richness, diversity, evenness and dominant concentration in the maize fields and there was a high similarity between the arthropods communities. The dynamic of the richness index, diversity index, evenness index, dominant concentration index and
\end{abstract}

收稿日期: 2018-11-23; 接受日期: 2019-02-28

基金项目: 转基因生物新品种培育重大专项(2016ZX08012005)、环保公益性行业科研专项(201509044)和中央民族大学一流大学一流学科项目 (Yldxxk201819)

* 共同通讯作者 Co-authors for correspondence. E-mail: liubiao@nies.org; xuekun@muc.edu.cn 
community similarity index of those arthropods in the maize fields tended to be consistent. Transformant DBN9936 has obvious resistance to Lepidopteron insects and has no significant negative effects on non-target arthropods. The results suggest that the transformant DBN9936 maize has no significant effect on community richness, diversity, evenness and dominance concentration of arthropods in the fields.

Key words: genetically modified maize; biodiversity; arthropods; diversity index; biosafety

自转基因作物商业化以来, 其在全球和国内的 种植面积逐年增长, 已取得显著的经济、生态和社 会效益(Shetty et al, 2018)。根据国际农业生物技术 应用服务组织 (The International Service for the Acquisition of Agri-biotech Application, ISAAA)的统 计, 2016年已有26个国家种植了1.851亿ha的转基因 作物, 较1996年增加了110倍。其中转基因玉米为种 植面积排第三位的作物, 种植面积已达到了全球玉 米总种植面积的26\%。国外转基因玉米的商业化生产 已有20年, 欧盟四国在2016年种植了超过 13.6 万ha 的转基因玉米(国际农业生物技术应用服务组织, 2017)。中国还未批准转基因玉米的商业化种植, 但 已经批准了转 $B t$ 基因抗虫玉米、抗除草剂品系进行 环境释放试验(朱莹等, 2017)。我国是全球第二大玉 米生产国和消费国, 玉米在我国播种面积大, 分布 广, 是重要的粮食与饲料作物(沈平等, 2016)。如果 转基因玉米引进并大面积种植的话, 将有可能改变 原有大田的生态环境和害虫的生存环境, 从而引起 一系列安全问题及非靶标效应(薛斿和张文国, 2008; 任振涛等, 2017)。

目前国内外关于转基因作物对非靶标节肢动 物影响的研究已进行了多年。如抗虫棉在对棉铃虫 (Helicoverpa armigera)具有较好抗性的同时, 对棉 田主要非标靶害虫也都有一定抑制作用, 对某些天 敌的种群存在不利影响, 而转基因耐盐碱棉花、转 基因抗病棉花和转基因抗旱棉花则对棉田节肢动 物多样性及食物网结构无显著影响(郭建英等, 2007; 郭佳惠等, 2016)。龟纹漂虫(Propylea japonica)取食 转 $B t$ 基因水稻花粉后, 其幼虫的发育历期有所延长, 但其存活率和繁殖能力没有受到不良影响(Zhang et al, 2014; Li et al, 2015)。也有研究显示转基因抗虫/ 抗除草剂大豆对田间节肢动物群落多样性无明显 影响(李凡等, 2013; Marques et al, 2018)。由此可见, 虽然关于转基因作物对非靶标节肢动物的影响已 有大量的报道, 但是依旧存在争议, 因此也需要对 不同的转基因作物采取“个案(case by case)”原则进 行研究。中国已拥有一批自主知识产权的转基因玉 米材料, 在这些转基因玉米获得安全证书产业化之 前, 必须对其安全性进行评估(康乐和陈明, 2013)。 本研究通过对转基因玉米大田中节肢动物种类和 数量的调查, 分析群落多样性的变化, 以期为转基 因玉米的生态安全性评价提供科学数据。

\section{材料与方法}

\section{1 试验材料}

试验于2015年及2017年5-9月在吉林省伊通满 族自治县试验基地进行, 种植的转基因玉米材料为 转EPSPS (耐草甘膦)和 Cry1Ab (抗虫) 基因的玉米 'DBN9936', 其受体品种为 'DBN318', 另外选择广 泛种植的常规玉米 ‘先玉335'作为对照。上述玉米材 料均由北京大北农生物技术有限公司提供。

\section{2 试验方法}

\subsection{1 种植小区设计}

本试验依据《农业部953号公告-10.4-2007》和 《农业部953号公告-11.4-2007》, 采用随机区组排 列和地块设置的方法。试验中设置12个小区, 每个 小区面积为 $150 \mathrm{~m}^{2}(10 \mathrm{~m} \times 15 \mathrm{~m})$, 在小区间设有 $1.0 \mathrm{~m}$ 宽的隔离带。玉米按条播的方式进行播种, 行 距60 cm, 株距 $25 \mathrm{~cm}$ 。处理设置为全生育期未喷施 除草剂的转基因玉米、喷施除草剂(参考专利: WO95/06128; U.S.5554798, 剂量为2倍剂量, 将除 草剂草甘膦420 g ae/ha的浓度定为 1 倍剂量)的转基 因玉米、未喷施除草剂的受体玉米和未喷施除草剂 的常规玉米, 每个处理重复3次。

\subsection{2 节肢动物调查}

采用对角线 5 点取样法在每个小区内设定 5 个取 样点。

使用直接观察法对植株上的节肢动物种类和 数量进行调查。从定苗 10 天至收获每 7 天调查 1 次, 每个取样点调查10株玉米。记录玉米植株上所有节 
肢动物的种类、数量及其发育阶段。对田间不能识 别的种类进行采集编号，带回室内鉴定，鉴定参考 蔡邦华(2015)的《昆虫分类学》。

使用陷阱调查法采集地表节肢动物。在玉米定 苗后第10天开始设置陷阱, 每14天调查1次, 至玉 米收获时调查结束。每取样点埋设 3 个陷阱 $(\Phi 7 \mathrm{~cm}$ $\times 8 \mathrm{~cm})$, 3 个陷阱之间的距离为 $0.5 \mathrm{~m}$, 共计 15 个陷 阱。陷阱结构: 使用 2 个一次性塑料杯镶嵌埋进玉米 田中，杯口与玉米地面保持平齐。陷阱溶剂： 5\%的 洗涤剂、5\%的酒精和 $90 \%$ 的水，陷阱中的溶剂量为 塑料杯容积的 $1 / 3$ 。过夜后调查陷阱中节肢动物的种 类和数量。对田间不能识别的种类进行采集编号, 带回室内鉴定。

于玉米成熟后收获前调查一次钻蛀害虫情况。 每个取样点选择 10 株玉米, 观察穗部, 并纵向剖开 茎秆, 查看茎秆内部是否有钻蛙类害虫, 记录害虫 种类、龄期、数量等, 通过活虫数、蛙孔数、虫龄、 钻蛙孔道长度及受害穗尖长度等指标, 量化钻蛀类 害虫对玉米材料的为害情况。

\subsection{3 数据分析}

采用Excel 2016、R 3.6.0、EstimateS v9.1.0、 Origin 2019 v9.60等软件进行各类多样性指数计算 和作图, 采用SPSS 23.0软件对试验数据进行统计 和单因素方差分析(One-way ANOVA)。节肢动物的 功能分类主要参考其食性分为害虫、捕食性天敌、 寄生性天敌和中性节肢动物。使用物种累积曲线判 断调查量的充分性, 利用Abundance-base Coverage Estimator (ACE)、非参数一阶刀切法(Jackknife1)以 及自助法(Bootstrap)估算玉米生育期田间节肢动物 的群落丰富度(李巧, 2011; Zou et al, 2015; 吴岗等, 2016)。群落相似性选择Sorenson相似性指数(相似性 指数为 1 时, 两个群落完全相同)和最小方差聚类分 析法。文中用到的各类指数的计算方法如下 (Magurran, 2013):

Margalef丰富度指数: $D_{m g}=\frac{S-1}{\ln N}$

Shannon-Wiener多样性指数: $H^{\prime}=-\sum_{i=1}^{S} P_{\mathrm{i}} \ln P_{\mathrm{i}}$

Simpson多样性指数: $D=1-\sum_{i=1}^{s} P_{\mathrm{i}}^{2}$
优势集中性指数: $C=\sum_{i=1}^{s}\left(\frac{N_{\mathrm{i}}}{N}\right)^{2}$

Sorenson群落相似性指数: $C^{\prime}=\frac{2 w}{a+b}$

Pielou均匀度指数: $J^{\prime}=\frac{H^{\prime}}{H_{\max }}=\frac{H^{\prime}}{\ln S}$

式中, $S$ 为物种数, $P_{\mathrm{i}}=N_{\mathrm{i}} / N, N_{\mathrm{i}}$ 为第 $\mathrm{i}$ 个物种的个体数, $N$ 为总个体数, $w$ 为两群落或样地共有物种数, $a 、 b$ 为两群落或样地各自的物种数。

\section{结果}

\section{1 玉米田节肢动物群落物种及功能群组成}

2015年和2017年玉米田植株和地表共记录节 肢动物个体 106,935 头, 其中未喷除草剂的 'DBN9936'、'DBN318'、“先玉335'和喷除草剂的 'DBN9936' 4 个玉米群落中分别有27,623、27,905、 26,281 和 26,126 头, 这些节肢动物隶属于 20 目 80 科 (附录1)。

2015年和2017年玉米生育期内，主要害虫是东 方粘虫(Mythimna separata)、亚洲玉米螟(Ostrinia furnacalis)、棉铃虫、玉米蚜(Rhopalosiphum maidis)、 双斑长跗萤叶甲(Monolepta hieroglyphica)以及圆 科和长角 科的节肢动物。捕食性天敌主要为小花 蝽(Orius similis)、龟纹㼼虫、异色漂虫(Harmonia axyridis)以及青步甲属(Chlaenius)、草蛉科、蟹蛛科、 园蛛科、幽灵蛛科的节肢动物。寄生性天敌主要是 寄生蜂类的昆虫, 数量较少。中性节肢动物主要包 括蚁科、蝇科的节肢动物。2015年和 2017 年, 'DBN9936'上鳞翅目害虫的数量均低于其他处理。 此外，2015年“先玉335’上叶甲科的数量显著低于其 他3个处理 $(P=0.047), 2017$ 年'DBN9936’ 上捕食性 天敌小花蝽的数量显著高于其他 3 个处理 $(P=$ 0.029)(表1)。

\section{2 物种累积曲线及田间节肢动物丰富度指数}

2015年和2017年玉米植株和地表节肢动物的 物种累积曲线如图1所示, 所有曲线均表现为上升 舒缓的典型抛物线，没有直线性上升的趋势，表明 这两年对玉米田间节肢动物种群的调查较充分。 ACE、Bootstrap和Jackknife1对丰富度的估算结果显 示，2015年和2017年实际调查结果占玉米田间节肢 动物估计真实值的 $80.98 \%$ 以上，其中 2017 年植株的 
表12015年和2017年4个玉米处理上节肢动物各功能群中主要类群的累积数量(头/50株)

Table 1 The cumulative number of main arthropods in the functional groups of four maize treatments in 2015 and 2017 (number of arthropods every 50 plants)

\begin{tabular}{|c|c|c|c|c|c|c|}
\hline $\begin{array}{l}\text { 功能群 } \\
\text { Functional groups }\end{array}$ & $\begin{array}{l}\text { 主要类群 } \\
\text { Major groups }\end{array}$ & 'DBN9936' & 'DBN318' & $\begin{array}{l}\text { ‘先玉335’ } \\
\text { Xianyu } 335\end{array}$ & $\begin{array}{l}\text { 'DBN9936'喷除草剂 } \\
\text { DBN9936 + herbicide }\end{array}$ & $P$ \\
\hline \multicolumn{7}{|l|}{2015} \\
\hline \multirow{5}{*}{$\begin{array}{l}\text { 主要害虫 } \\
\text { Main pest }\end{array}$} & 鳞翅目 Lepidopteron & $10.3 \pm 2.6^{\mathrm{a}}$ & $20.0 \pm 3.2^{\mathrm{a}}$ & $21.0 \pm 8.9^{\mathrm{a}}$ & $6.0 \pm 1.5^{\mathrm{a}}$ & 0.166 \\
\hline & 长角 科 Entomobryidae & $112.3 \pm 25.5^{\mathrm{a}}$ & $105.7 \pm 9.9^{\mathrm{a}}$ & $128.3 \pm 11.3^{\mathrm{a}}$ & $113.7 \pm 8.1^{\mathrm{a}}$ & 0.765 \\
\hline & 蚜科 Aphididae & $834.0 \pm 206.6^{\mathrm{a}}$ & $763.3 \pm 118.3^{\mathrm{a}}$ & $515.7 \pm 62.1^{\mathrm{a}}$ & $590.0 \pm 84.3^{\mathrm{a}}$ & 0.341 \\
\hline & 叶甲科 Chrysomelidae & $1,194.0 \pm 94.4^{\mathrm{b}}$ & $1,308.7 \pm 32.9^{\mathrm{b}}$ & $1,009.7 \pm 56.4^{\mathrm{a}}$ & $1,217.3 \pm 42.9^{b}$ & 0.047 \\
\hline & 总和 Total & $2,212.3 \pm 266.9^{\mathrm{a}}$ & $2,258.0 \pm 154.5^{\mathrm{a}}$ & $1,736.0 \pm 37.8^{\mathrm{a}}$ & $1,985.7 \pm 109.9^{\mathrm{a}}$ & 0.176 \\
\hline \multirow{5}{*}{$\begin{array}{l}\text { 捕食性天敌 } \\
\text { Predatory natural enemy }\end{array}$} & 蜘蛛目 Araneida & $43.7 \pm 4.6^{\mathrm{a}}$ & $52.3 \pm 2.2^{\mathrm{a}}$ & $59.3 \pm 3.8^{\mathrm{a}}$ & $54.3 \pm 7.7^{\mathrm{a}}$ & 0.246 \\
\hline & 漂虫科 Coccinellidae & $113.7 \pm 6.1^{\mathrm{a}}$ & $106.3 \pm 11.2^{\mathrm{a}}$ & $104.3 \pm 7.9^{\mathrm{a}}$ & $120.0 \pm 15.1^{\mathrm{a}}$ & 0.720 \\
\hline & 草蛉科 Chrysopidae & $36.3 \pm 6.2^{\mathrm{a}}$ & $32.3 \pm 2.8^{\mathrm{a}}$ & $25.3 \pm 4.1^{\mathrm{a}}$ & $25.3 \pm 4.1^{\mathrm{a}}$ & 0.288 \\
\hline & 步甲科 Carabidae & $12.7 \pm 2.9^{\mathrm{a}}$ & $15.0 \pm 3.2^{\mathrm{a}}$ & $20.7 \pm 9.9^{\mathrm{a}}$ & $20.0 \pm 6.5^{\mathrm{a}}$ & 0.808 \\
\hline & 总和 Total & $214.7 \pm 8.6^{\mathrm{a}}$ & $213.3 \pm 10.3^{\mathrm{a}}$ & $219.7 \pm 3.8^{\mathrm{a}}$ & $231.0 \pm 5.5^{\mathrm{a}}$ & 0.386 \\
\hline $\begin{array}{l}\text { 寄生性天敌 } \\
\text { Parasitic natural enemy }\end{array}$ & 总和 Total & $8.7 \pm 3.3^{\mathrm{a}}$ & $6.7 \pm 1.9^{\mathrm{a}}$ & $5.7 \pm 0.9^{\mathrm{a}}$ & $7.7 \pm 0.9^{\mathrm{a}}$ & 0.742 \\
\hline $\begin{array}{l}\text { 中性节肢动物 } \\
\text { Neutral arthropod }\end{array}$ & 总和 Total & $206.7 \pm 31.5^{\mathrm{a}}$ & $177.7 \pm 9.0^{\mathrm{a}}$ & $152.0 \pm 28.6^{\mathrm{a}}$ & $147.0 \pm 20.4^{\mathrm{a}}$ & 0.339 \\
\hline \multicolumn{7}{|l|}{2017} \\
\hline 主要害虫 & 鳞翅目 Lepidopteron & $3.3 \pm 1.7^{\mathrm{a}}$ & $24.0 \pm 6.0^{\mathrm{b}}$ & $26.7 \pm 2.0^{\mathrm{b}}$ & $17.0 \pm 0.6^{\mathrm{a}}$ & 0.005 \\
\hline \multirow[t]{4}{*}{ Main pest } & 蚜科 Aphididae & $5,357.0 \pm 148.5^{\mathrm{a}}$ & $5,408.3 \pm 324.9^{\mathrm{a}}$ & $5,444.0 \pm 607.7^{\mathrm{a}}$ & $4,751.7 \pm 171.3^{\mathrm{a}}$ & 0.520 \\
\hline & 叶甲科 Chrysomelidae & $42.3 \pm 3.8^{\mathrm{a}}$ & $51.0 \pm 4.6^{\mathrm{a}}$ & $40.0 \pm 3.5^{\mathrm{a}}$ & $46.7 \pm 1.5^{\mathrm{a}}$ & 0.213 \\
\hline & 长角 科 Entomobryidae & $86.3 \pm 9.8^{\mathrm{a}}$ & $95.0 \pm 12.5^{\mathrm{a}}$ & $93.4 \pm 6.6^{\mathrm{a}}$ & $97.0 \pm 10.0^{\mathrm{a}}$ & 0.882 \\
\hline & 总和 Total & $5,880.7 \pm 133.5^{\mathrm{a}}$ & $5,974.7 \pm 334.9^{\mathrm{a}}$ & $6,011.7 \pm 592.7^{\mathrm{a}}$ & $5,321.7 \pm 185.8^{a}$ & 0.526 \\
\hline 捕食性天敌 & 蜘蛛目 Araneida & $87.0 \pm 8.5^{\mathrm{a}}$ & $97.7 \pm 12.1^{\mathrm{a}}$ & $88.0 \pm 3.5^{\mathrm{a}}$ & $86.3 \pm 5.2^{\mathrm{a}}$ & 0.732 \\
\hline \multirow[t]{5}{*}{ Predatory natural enemy } & 漂虫科 Coccinellidae & $235.7 \pm 8.7^{\mathrm{a}}$ & $211.3 \pm 34.0^{\mathrm{a}}$ & $221.3 \pm 21.9^{\mathrm{a}}$ & $250.7 \pm 10.4^{\mathrm{a}}$ & 0.607 \\
\hline & 草蛉科 Chrysopidae & $51.0 \pm 6.5^{\mathrm{a}}$ & $41.0 \pm 7.0^{\mathrm{a}}$ & $39.0 \pm 3.5^{\mathrm{a}}$ & $54.0 \pm 6.7^{\mathrm{a}}$ & 0.295 \\
\hline & 步甲科 Carabidae & $36.7 \pm 4.5^{\mathrm{a}}$ & $49.7 \pm 7.5^{\mathrm{a}}$ & $39.0 \pm 5.6^{\mathrm{a}}$ & $45.7 \pm 7.1^{\mathrm{a}}$ & 0.481 \\
\hline & 小花蝽 Orius sauteri & $57.3 \pm 2.3^{b}$ & $36.7 \pm 4.3^{\mathrm{a}}$ & $39.7 \pm 0.9^{\mathrm{a}}$ & $39.7 \pm 6.8^{\mathrm{a}}$ & 0.029 \\
\hline & 总和 Total & $510.7 \pm 22.0^{\mathrm{a}}$ & $481.3 \pm 15.2^{\mathrm{a}}$ & $476.7 \pm 23.7^{\mathrm{a}}$ & $522.0 \pm 11.8^{\mathrm{a}}$ & 0.298 \\
\hline $\begin{array}{l}\text { 寄生性天敌 } \\
\text { Parasitic natural enemy }\end{array}$ & 总和 Total & $7.3 \pm 1.8^{\mathrm{a}}$ & $9.0 \pm 3.8^{\mathrm{a}}$ & $8.0 \pm 0.6^{\mathrm{a}}$ & $7.0 \pm 2.0^{\mathrm{a}}$ & 0.933 \\
\hline $\begin{array}{l}\text { 中性节肢动物 } \\
\text { Neutral arthropod }\end{array}$ & 总和 Total & $166.7 \pm 22.0^{\mathrm{a}}$ & $181.0 \pm 8.6^{\mathrm{a}}$ & $150.7 \pm 5.5^{\mathrm{a}}$ & $153.3 \pm 25.2^{\mathrm{a}}$ & 0.613 \\
\hline
\end{tabular}

同一行数据中不同小写字母表示不同处理间存在显著差异 $(P<0.05)$

Different lowercases in the same row represent significant difference among treatments $(P<0.05)$

调查结果占比达到了 $95.11 \%$, 说明这两年对玉米田 间节肢动物多样性调查结果的可靠度比较高, 对植 株的调查结果比地表更接近真实值(表2)。

对比图1中 4 个处理物种累积曲线的最大值, ‘DBN318’和 ‘先玉 335’略高于 ‘DBN9936’，但置 信区间有重叠, 差异较小。说明‘DBN318’和‘先玉 335’的物种丰富度略高于‘DBN9936’。在调查结果 中‘DBN9936’上几乎没有鳞翅目昆虫的分布, 因此 导致其丰富度相较于另外两种玉米略有降低(图1)。
2015年4种处理玉米植株上节肢动物群落的丰 富度在7月末到8月中旬降低，随后呈现缓慢上升的 趋势，地表丰富度呈稳定的缓慢上升的状态; 2017年 植株和地表节肢动物群落的物种丰富度指数随时间 呈现上升、下降、再上升、再下降的“双峰”模式, 6 月下旬和 8 月中旬达到最高水平。转化体 'DBN9936'、受体 ‘DBN318'、“先玉335’和喷施除草 剂的'DBN9936’ 4 个处理的玉米田间节肢动物的动 态变化趋势基本一致, 可认为转基因玉米‘DBN9936’ 

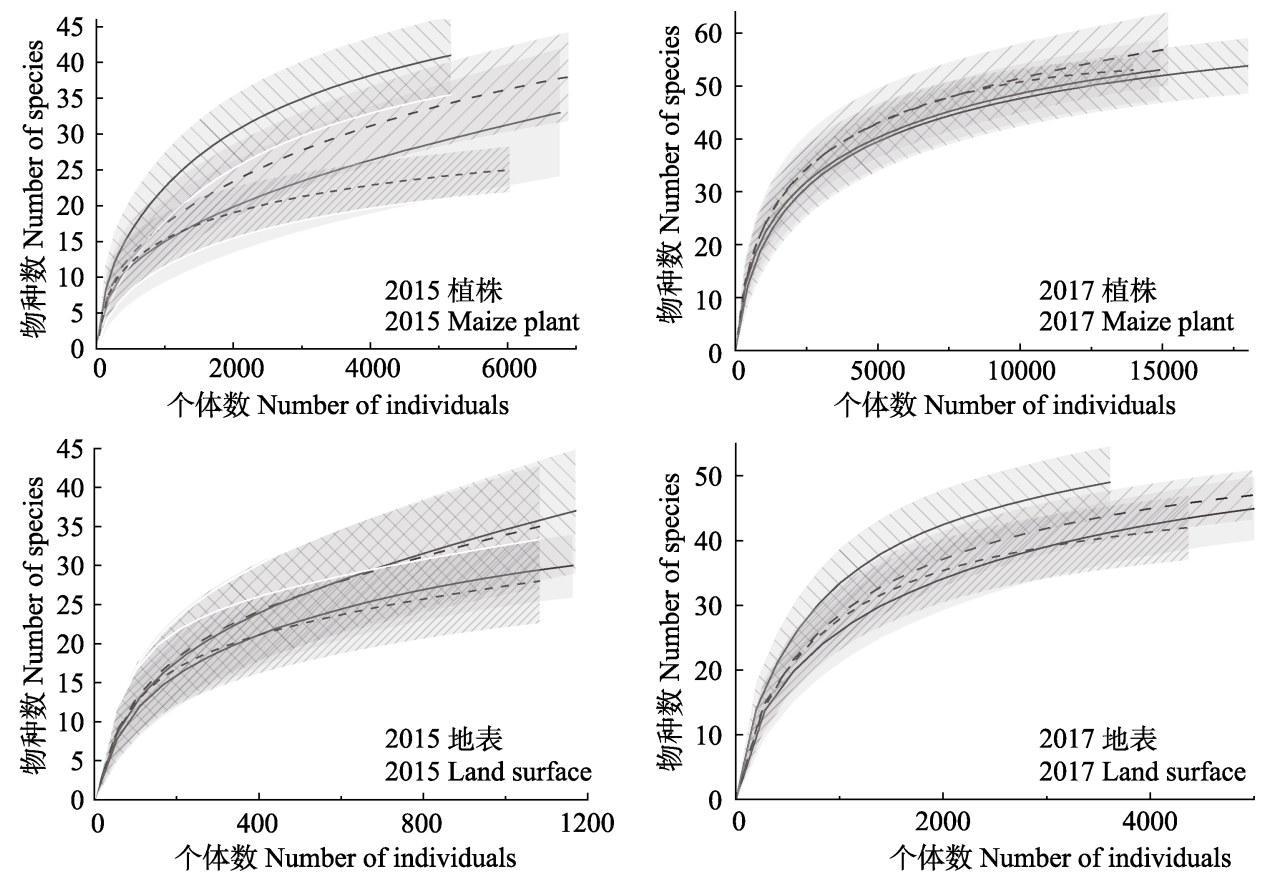

- 'DBN9936' - -

'DBN318'

‘先玉335’ Xianyu335 - -

'DBN9936'喷除草剂 DBN9936 + herbicide

图12015年和2017年4个玉米处理节肢动物的物种累积曲线

Fig. 1 Species accumulation curves of arthropods of four maize treatments in 2015 and 2017

表2 2015年和2017年不同玉米处理上节肢动物物种丰富度 Table 2 Species richness index of arthropods of different maize treatments in 2015 and 2017

\begin{tabular}{lcllll}
\hline & $\begin{array}{l}\text { ACE } \\
\text { 指数 } \\
\text { ACE } \\
\text { Index }\end{array}$ & $\begin{array}{l}\text { Bootstrap } \\
\text { 指数 } \\
\text { Bootstrap } \\
\text { Index }\end{array}$ & $\begin{array}{l}\text { Jackknife 1 } \\
\text { 指数 } \\
\text { Jackknife 1 } \\
\text { Index }\end{array}$ & $\begin{array}{l}\text { 实际物 } \\
\text { 种数 } \\
\text { Number } \\
\text { of species }\end{array}$ & $\begin{array}{l}\text { 比例 } \\
\text { Ratio } \\
(\%)\end{array}$ \\
\hline $\begin{array}{l}\text { 2015 } \\
\text { 植株 } \\
\text { Maize plant } \\
\text { 地表 }\end{array}$ & 51.49 & 54.25 & 58.88 & 48 & 88.87 \\
$\begin{array}{l}\text { Land surface } \\
\text { 总体 Total }\end{array}$ & 58.26 & 51.41 & 54.96 & 49 & 88.25 \\
$\begin{array}{l}\text { 2017 } \\
\text { 植株 }\end{array}$ & 71.07 & 71.32 & 72.97 & 68 & 95.11 \\
$\begin{array}{l}\text { Maize plant } \\
\text { 地表 }\end{array}$ & 78.65 & 64.66 & 72.81 & 59 & 80.98 \\
$\begin{array}{l}\text { Land surface } \\
\text { 总体 Total }\end{array}$ & 93.36 & 88.45 & 93.95 & 83 & 89.92 \\
\hline
\end{tabular}

ACE, Abundance-base Coverage Estimator

对玉米田间节肢动物的物种丰富度没有明显影响 (图2)。

\section{3 田间节肢动物群落相似性指数及聚类分析}

通过比较转化体玉米 ‘DBN9936’与受体玉米 'DBN318'、转化体玉米'DBN9936'与喷施除草剂的 转化体玉米‘DBN9936’、受体玉米‘DBN318’与常规
玉米·先玉335’以及受体玉米‘DBN318’与喷施除草 剂的转化体玉米 ‘DBN9936’，得到4条群落相似性 指数随时间变化的曲线(图3)。2015年和2017年植株 上群落间相似度在初期较低( 0.4 左右 $)$, 之后升高并 维持在较高的水平(0.8左右)。而不同处理间地表节 肢动物的群落相似度除了在2015年7月有一个骤降 之外, 一直稳定维持在较高水平 $(0.7$ 左右 $)$ 。总体上 看, 两年各处理的田间节肢动物群落相似程度较高。 整个生育期转化体 'DBN9936'与受体'DBN318' 间在 2015年和2017年的相似性指数分别为 0.938 、 0.980, 转化体 'DBN9936' 与转化体 'DBN9936'喷施 除草剂分别为 $0.918 、 0.934$, 受体 'DBN318'与常规 玉米·先玉335’分别为 $0.858 、 0.981$, 受体“DBN318’ 与转化体 'DBN9936' 喷施除草剂分别为 0.920 、 0.930。从结果可以看出, 两年不同处理转基因玉米 田之间的相似性程度都很高(均大于 $85 \%$ ), 2017年 各处理间群落相似性程度更高。

采用最小方差法对节肢动物群落进行聚类分 析的结果如图4所示, 2017年地表和植株的节肢动 物聚为一类, 2015年地表和植株的节肢动物聚为一类, 说明在这两年玉米田间节肢动物组成差异较大。在 2017年植株的聚类支上, 转化体玉米‘DBN9936’和 

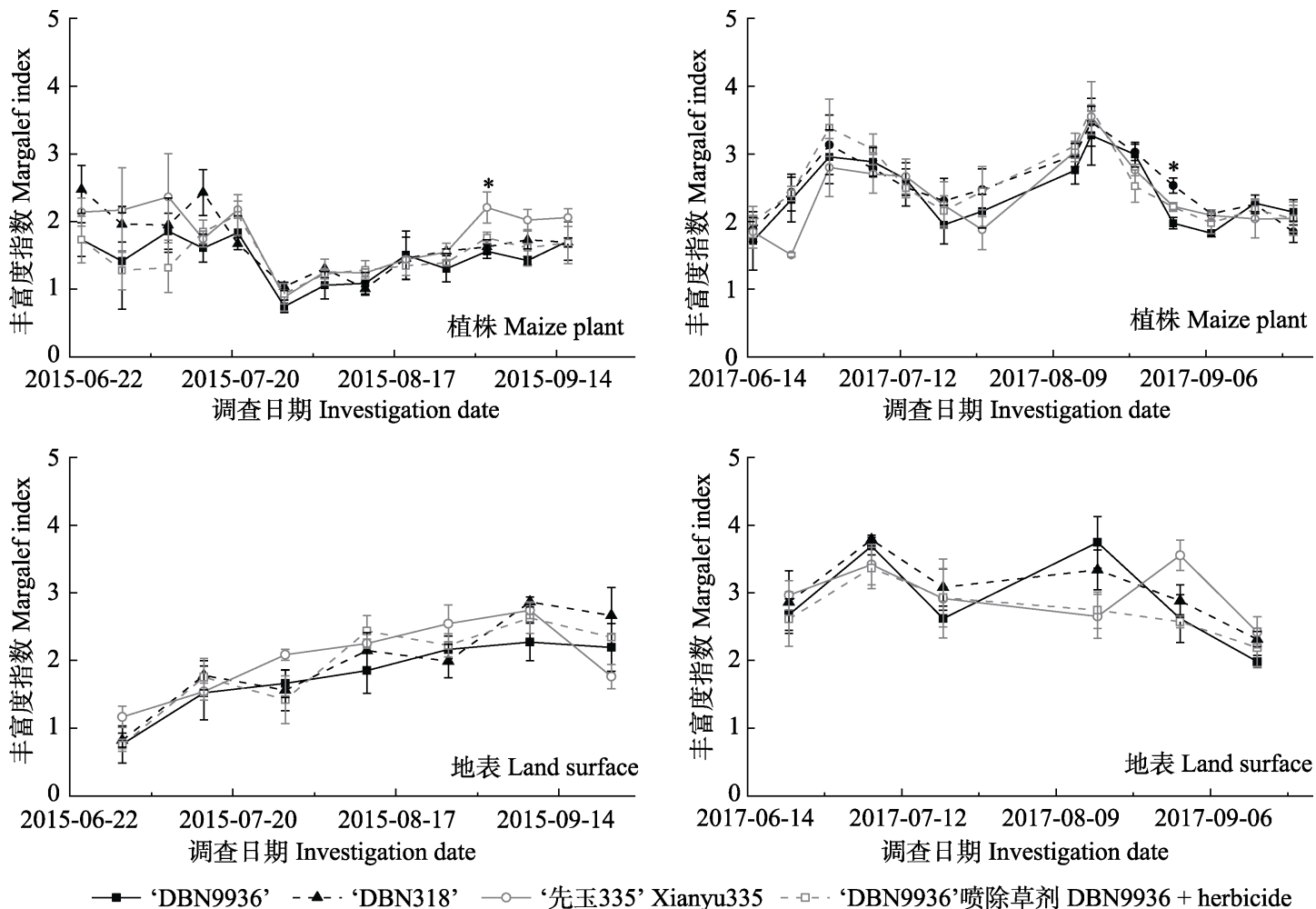

图2 2015年和2017年4个玉米处理节肢动物群落物种丰富度动态

Fig. 2 The Margalef index dynamics of arthropod community of four maize treatments in 2015 and 2017
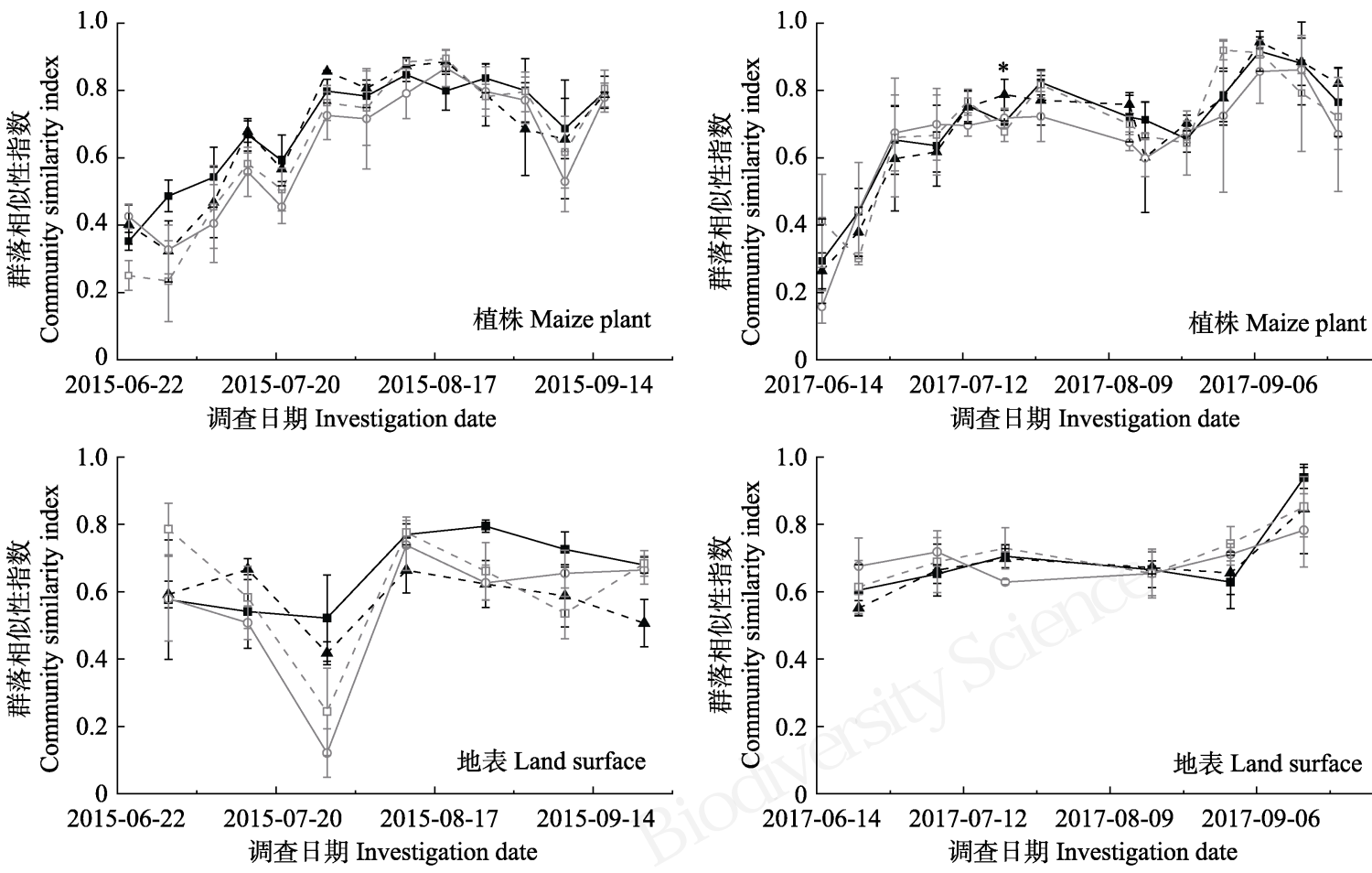

$\rightarrow-$ 'DBN9936' vs 'DBN318' - _- . 'DBN9936' vs 'DBN9936' + herbicide

- 'DBN318' vs Xianyu335 _ - 'DBN318' vs 'DBN9936' + herbicide

图3 2015年和2017年4个玉米处理节肢动物群落相似性指数动态

Fig. 3 The community similarity index dynamics of arthropod community of four maize treatments in 2015 and 2017 


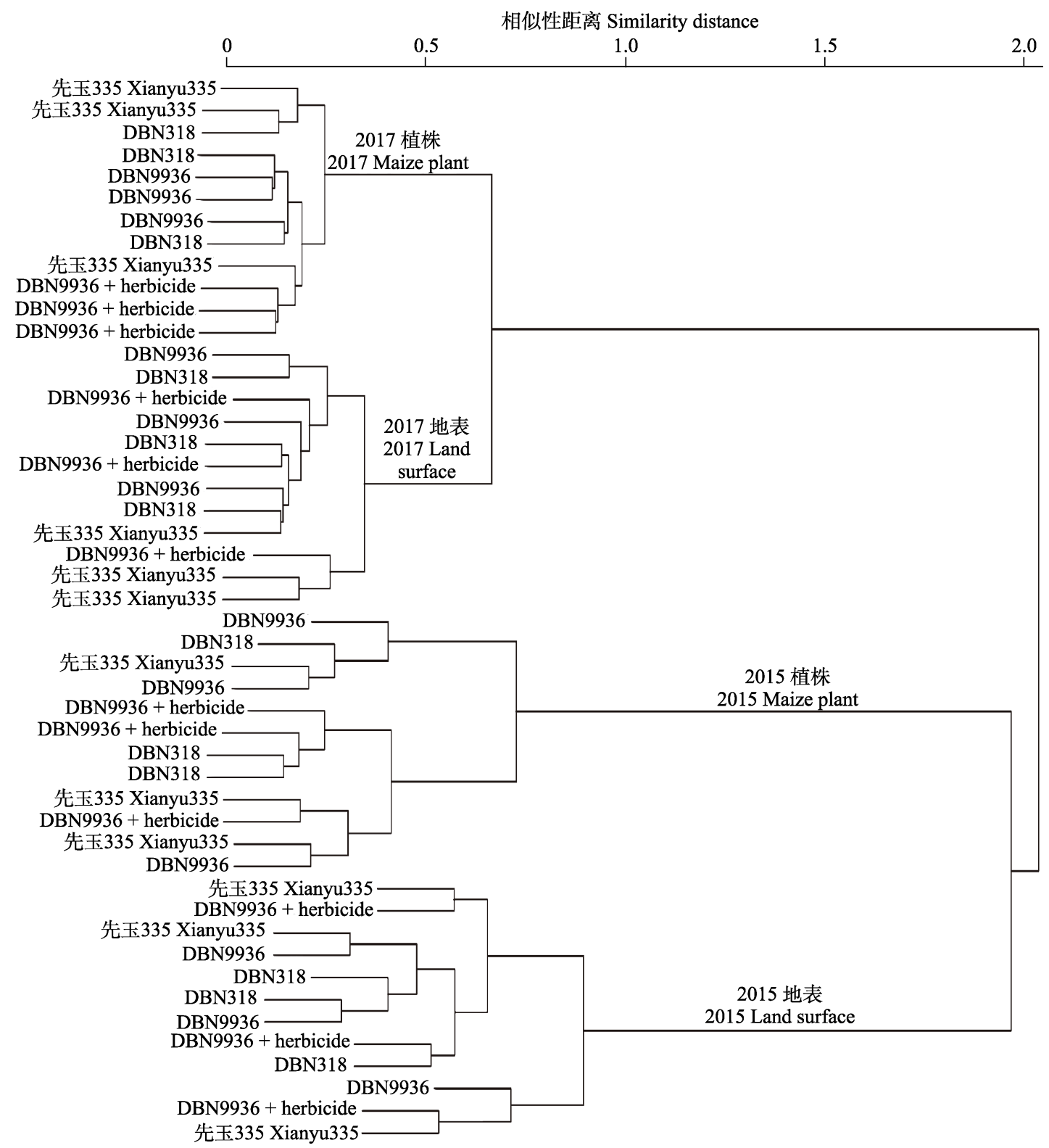

图4 2015年和2017年4个玉米处理上节肢动物群落聚类结果。每个玉米处理具有3个重复试验, 节肢动物种类和数量的相似 度越高的样地, 其聚类支靠的越近。

Fig. 4 The clustering results of the arthropod communities of four maize treatments in 2015 and 2017. Each maize treatment has 3 replicates. The higher the similarity of arthropod species and quantity is, the closer the clustering branches is.

喷施除草剂的转化体玉米'DBN9936'各自聚为一类, 说明二者植株的节肢动物群落结构存在一定的差 异。在别的聚类支中每一种处理的3个平行均未聚 为一类。结合功能群分类统计结果, 2015年和2017 年间转化体‘DBN9936’上鳞翅目害虫的数量均低于 其他处理, 但2015年的统计结果未见显著性差异, 同时地表基本没有鳞翅目昆虫, 因此推测造成这种 差异的主要原因为鳞翅目昆虫的分布, 说明各类玉 米的种植对地表节肢动物的分布没有明显影响。

\section{4 田间节肢动物群落多样性指数}

玉米田间节肢动物群落的Shannon-Wiener指数 和Simpson指数随时间的动态变化基本一致。以 Shannon-Wiener指数为例, 2015年植株多样性指数 在7月上旬和下旬较高, 7月末急剧下降, 之后逐渐 回升。地表节肢动物群落多样性指数在初期较低, 之后呈逐渐上升状态，在7月末略有波动; 2017年植 株上的多样性指数在调查期间基本呈现升高、降低、 升高、再降低、再升高的趋势, 7月20日和9月7日的 

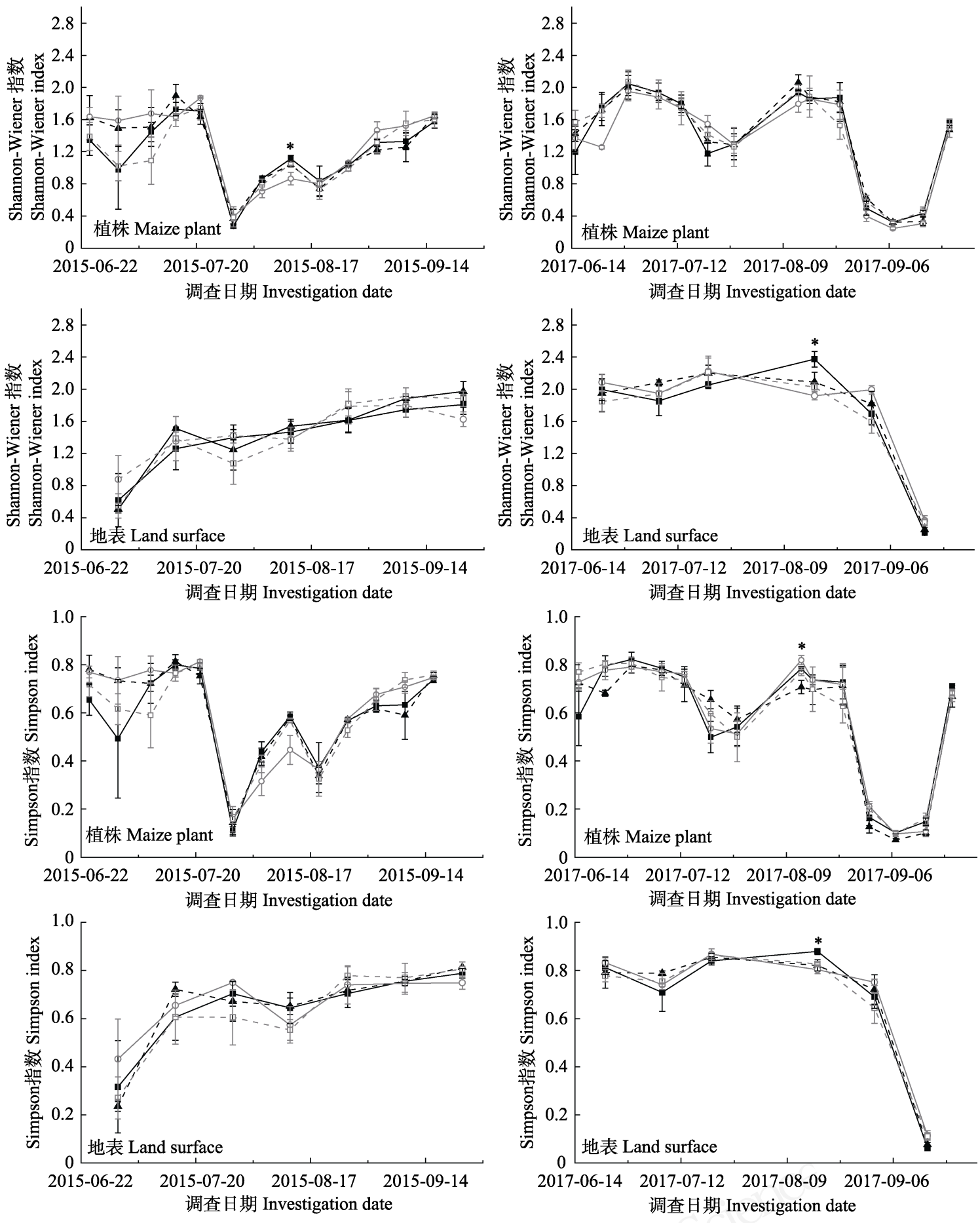

——DBN9936' - - - 'DBN318' —— ‘先玉335' Xianyu335 - - - 'DBN9936'喷除草剂 DBN9936 + herbicide

\section{图5 2015年和2017年4个玉米处理上田间节肢动物群落多样性指数动态}

Fig. 5 The biodiversity index dynamics of arthropod community of four maize treatments in 2015 and 2017

多样性指数降到最低。地表节肢动物群落多样性则 一直稳定维持在较高的状态, 在 9 月 7 日骤降到最 低。但从整体上看, 各类玉米田植株和地表的多样性 指数变化动态基本趋于一致, 各处理间差异较小。

\section{5 田间节肢动物群落均匀度指数}

Pielou均匀度指数的动态变化如图6所示。植株 上节肢动物均匀度指数的变化范围在0.09-1.00之 间，地表节肢动物均匀度指数的变化范围是 $0.20-$ 
1.00。2015年7月底至8月中旬玉米植株节肢动物群 落均匀度指数急剧降低后缓慢上升, 地表均匀度在 初期呈现上升的状态，7月末之后保持稳定，在8月 中旬略有波动。2017年玉米植株和地表节肢动物均 匀度均呈现7月上旬略有下降，9月上旬显著下降的 趋势。但从整体上看，所有处理植株和地表节肢动 物群落的均匀度指数的变化动态趋于一致, 也就是 说转基因玉米“DBN9936”对玉米田间节肢动物群落 的均匀度没有明显的影响。

\section{6 田间节肢动物群落优势集中性指数}

节肢动物群落的优势集中性指数统计结果如 图7所示，2015年7月末和8月中旬玉米植株上的节 肢动物优势集中性指数较高, 呈现双峰模式, 而地 表统计结果呈现由较高水平逐渐降低的趋势，8月 中旬有一个较小的波动; 2017年的玉米植株优势集 中性统计结果图中有两个明显的峰值, 第一个是在 7月20日到7月27日，第二个是在8月31日到9月15日， 地表节肢动物的优势集中性指数较为稳定，7月6日 有一个较小的波动, 9月15日优势集中性指数骤增。 从整体上看, 4 个处理植株和地表优势集中性指数动 态变化趋于一致, 说明转基因玉米对玉米田间节肢
动物的优势集中性没有明显的影响。

\section{7 玉米剖秆结果}

玉米剖秆的统计结果显示(表3), 主要的钻蛙类 害虫包括亚洲玉米蛽和棉铃虫。它们的活虫数、蛙 孔数以及钻蛙隧道长度等数据的统计结果显示: 两 年间喷施和未喷施除草剂的转化体玉米 'DBN9936” 在蛙孔数、活虫数、隧道和穗尖的被害长度以及最 长长度上均低于受体 ‘DBN318’ 和常规品种“先玉 335，各类指标均表现出对钻蛙类害虫的抗性。

\section{3 讨论}

试验设计中除了转化体 'DBN9936’、受体 'DBN318' 和常规“先玉335'外，还有一个'DBN9936' 喷除草剂的处理，这个处理的意义主要在于：(1)转 化体玉米是抗虫抗除草剂双抗玉米，可验证转入基 因的功能; (2)在实际大田种植中也会喷施除草剂, 这是对实际大田种植的模拟。

\section{1 节肢动物功能群在 4 个处理间的差异}

2015年和2017年的田间节肢动物功能群分类 统计的结果表明，转化体 'DBN9936’上鳞翅目害虫 的数量均低于其他处理, 说明转基因玉米
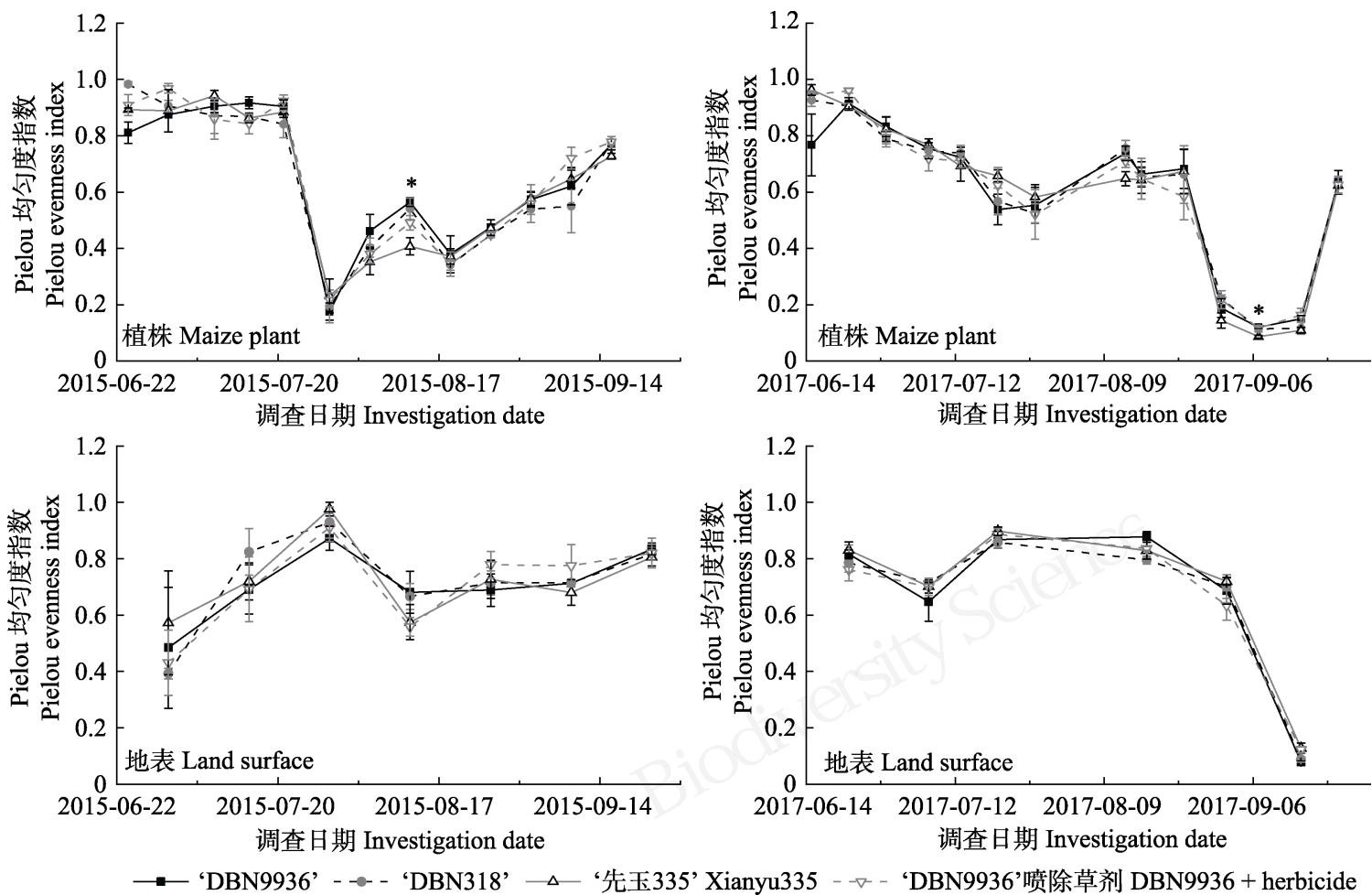

图6 2015年和2017年4个玉米处理上田间节肢动物群落Pielou均匀度指数动态

Fig. 6 The Pielou evenness index dynamics of arthropod community of four maize treatments in 2015 and 2017 

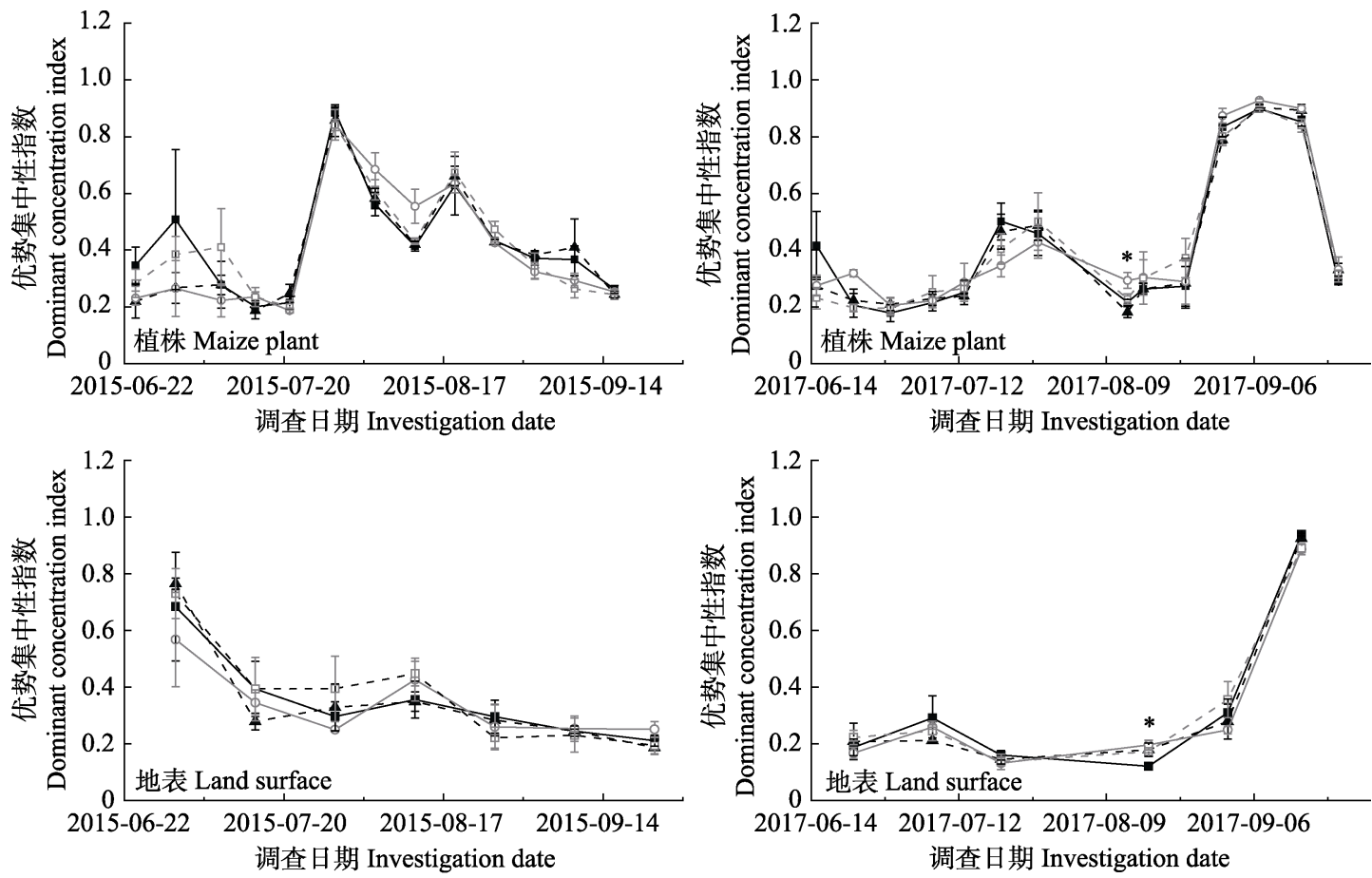

——DBN9936' - - - 'DBN318' ——先玉335’ Xianyu335 - - - 'DBN9936'喷除草剂 DBN9936 + herbicide

图7 2015年和2017年4个玉米处理上田间节肢动物群落优势集中性指数动态

Fig. 7 The dominant concentration index dynamics of arthropod community of four maize treatments in 2015 and 2017

表3 2015年和2017年4个处理玉米的亚洲玉米螟和棉铃虫为害情况

Table 3 Damage degree of four maize treatment by Ostrinia furnacalis and Helicoverpa armigera in 2015 and 2017

\begin{tabular}{|c|c|c|c|c|}
\hline 为害指标 Damage parameter and degree & 'DBN9936' & 'DBN318' & $\begin{array}{l}\text { ‘先玉335’ } \\
\text { Xianyu } 335\end{array}$ & $\begin{array}{l}\text { 'DBN9936'喷除草剂 } \\
\text { DBN9936 + herbicide }\end{array}$ \\
\hline \multicolumn{5}{|l|}{2015} \\
\hline 蛙孔数(个/50株) Number of apertures every 50 plants & $0.0 \pm 0.0^{\mathrm{b}}$ & $14.3 \pm 1.2^{\mathrm{a}}$ & $22.0 \pm 4.0^{\mathrm{a}}$ & $0.0 \pm 0.0^{\mathrm{b}}$ \\
\hline 活虫数(头/50株) Number of alive borers every 50 plants & $0.3 \pm 0.3^{\mathrm{b}}$ & $10.3 \pm 1.0^{\mathrm{a}}$ & $12.5 \pm 1.9^{\mathrm{a}}$ & $0.3 \pm 0.3^{\mathrm{b}}$ \\
\hline 最长隧道长度 Maximum tunnel length $(\mathrm{cm})$ & 0.0 & 16.5 & 13.0 & 0.0 \\
\hline 平均隧道长度 Average tunnel length (cm) & - & $6.50 \pm 0.56^{\mathrm{b}}$ & $4.97 \pm 0.40^{\mathrm{a}}$ & - \\
\hline 最长穗尖被害长度 Maximum damage length of spike tip (cm) & 5.5 & 7.0 & 8.0 & 4.0 \\
\hline 平均穗尖被害长度 Average damage length of spike tip (cm) & $2.33 \pm 1.59^{\mathrm{a}}$ & $3.01 \pm 0.21^{\mathrm{a}}$ & $2.98 \pm 0.20^{\mathrm{a}}$ & $1.94 \pm 0.39^{\mathrm{a}}$ \\
\hline \multicolumn{5}{|l|}{2017} \\
\hline 蛀孔数(个/50株) Number of apertures every 50 plants & $8.0 \pm 7.9^{\mathrm{a}}$ & $16.0 \pm 8.1^{\mathrm{a}}$ & $8.7 \pm 2.4^{\mathrm{a}}$ & $5.3 \pm 1.8^{\mathrm{a}}$ \\
\hline 活虫数(头/50株) Number of alive borers every 50 plants & $3.3 \pm 0.3^{\mathrm{a}}$ & $10.7 \pm 0.5^{\mathrm{a}}$ & $6.0 \pm 0.1^{\mathrm{a}}$ & $2.7 \pm 0.2^{\mathrm{a}}$ \\
\hline 最长隧道长度 Maximum tunnel length $(\mathrm{cm})$ & 13.5 & 20.0 & 20.8 & 7.0 \\
\hline 平均隧道长度 Average tunnel length $(\mathrm{cm})$ & $2.97 \pm 2.97^{\mathrm{a}}$ & $5.92 \pm 2.87^{\mathrm{a}}$ & $3.68 \pm 4.06^{\mathrm{a}}$ & $0.87 \pm 0.49^{\mathrm{a}}$ \\
\hline 最长穗尖被害长度 Maximum damage length of spike tip (cm) & 9.0 & 27.4 & 22.8 & 16.8 \\
\hline 平均穗尖被害长度 Average damage length of spike tip (cm) & $2.39 \pm 1.74^{\mathrm{a}}$ & $6.24 \pm 1.23^{\mathrm{a}}$ & $8.18 \pm 2.36^{\mathrm{a}}$ & $3.76 \pm 3.42^{\mathrm{a}}$ \\
\hline
\end{tabular}

同一行数据中不同小写字母表示不同处理间存在显著差异 $(P<0.05)$

Different lowercases in the same row represent significant difference among treatments $(P<0.05)$

'DBN9936'对靶标害虫有较强的抑制作用，控制了 靶标害虫的发生。2015年叶甲在“先玉335’上的分布 显著低于其他处理, 2017年虽未见显著性差异, 但
具有相同的趋势，即“先玉335’上叶甲的分布低于其 他处理。分析原因可能是由于 2015 年气候较为干旱 少雨，双斑长跗萤叶甲暴发，在整个生育期的平均 
数量达到了24头/株。2017年气候变化大降雨多, 双 斑长跗萤叶甲在整个生育期的平均数量仅为 1 头/株, 所以2017年的结果未见显著性差异但在 ‘先玉335’ 上有相似的分布趋势。此外, 2017年转化体玉米 'DBN9936' 上捕食性天敌小花蝽的数量显著增加, 2015年小花蝽的数量非常少, 平均数量仅为 0.12 头/ 株, 统计结果没有生物学意义, 但除小花蝽外, 其 他的主要捕食性天敌及捕食性天敌的总数在各处 理间均无显著性差异, 说明转基因玉米 'DBN9936” 对玉米田生态系统的天敌组成无明显影响。其他害 虫、寄生性天敌和中性节肢动物的数量在各处理间 均无明显差异, 说明转基因玉米 'DBN9936'对非靶 标节肢动物没有明显影响。

\section{2 节肢动物群落各类多样性指数在 4 个处理间的} 差异及其随时间变化的动态与气候的关系

田间节肢动物群落多样性指数的分析结果表 明，在整个调查期间不同地块间多样性指数的变化 趋势一致，但在不同的时期多样性指数整体上会出 现明显的波动, 主要受到玉米田两个优势种(双斑 长跗萤叶甲、玉米蚜)以及气候的影响。2015年气候 干旱少雨, 双斑长跗萤叶甲较高的种群密度从7月 末一直持续到8月中旬结束, 玉米蚜则在8月持续保 持在较高水平, 8月中旬达到最高水平，这导致了玉 米植株节肢动物的丰富度、多样性和均匀度均在7 月末出现了明显的下降，8月缓慢上升，8月中旬出 现了一个较小的波动。双斑长跗萤叶甲和玉米蚜在 地表鲜有分布, 所以地表的调查结果显示其丰富 度、多样性和均匀度基本呈现缓慢上升的趋势, 优 势集中性反之，在7月末和8月中旬有小的波动但不 明显。2017年的调查从6月15日开始，在6月15日到 22日之间植株节肢动物物种丰富度和多样性有一 个明显的上升, 推测是由于随着节肢动物生育期到 来, 其种类和数量的增加所致。在 7 月 13 日到 8 月 3 日，玉米田间节肢动物的丰富度、多样性、均匀度 出现明显的下降而优势集中性出现明显的上升, 结 合节肢动物数据和气象数据记录, 在此期间出现了 降雨和双斑长跗萤叶甲的增加, 降雨对植株物种丰 度影响较大, 而通过计算验证, 多样性、优势集中 性和均匀度主要受双斑长跗萤叶甲数量的影响, 如 果去掉双斑长跗茧叶甲的数量后再计算这三种指 数, 将会发现多样性指数在该时间段的变化较小, 同时地表的这三种指数也会相对稳定一些。在 8 月
31日到9月15日，玉米田间节肢动物的丰富度、多样 性、均匀度出现明显的下降，优势集中性出现明显 的上升，结合记录，在这段时间气温开始下降并且 玉米蚜暴发，从9月1日的平均34.8头/50株到9月15 日的平均 $1,032.9$ 头/50株, 其中气温的下降会导致 物种种类和数量的下降。玉米田间节肢动物的丰富 度主要受气温的影响, 而多样性、均匀度和优势集 中性受两者的共同作用，因为在 9 月 15 日之后，随 着玉米的成熟，玉米蚜迁飞，多样性和均匀度回升， 优势集中性指数下降, 而丰富度指数持续下降。

\section{3 抗虫转基因玉米可能带来的生态学影响}

抗虫转基因作物对田间节肢动物可能的影响 主要包括：(1)对非靶标节肢动物的直接毒害作用。 在本次试验中，未见转基因玉米“DBN9936’对除鳞 翅目外的害虫有明显的毒害作用，这与Skoková等 (2015)、Arias-Martín等(2016)、Guo等(2016)、尹俊 琦等(2017)的研究结果一致。(2)鳞翅目害虫对 $B t$ 蛋 白产生抗性。大多数研究表明鳞翅目昆虫在转 $B t$ 基 因作物连续种植多年后，对 $B t$ 蛋白的抗性水平会逐 渐增加, 有研究发现美洲棉铃虫(Helicoverpa zea)、 红铃虫 (Pectinophora gossypiella)、草地贪夜蛾 (Spodoptera frugiperda)等均会对某些Bt蛋白产生一 定的抗性(Tabashnik et al, 2008; Storer et al, 2010; Carrière et al, 2018)。在我们的研究中, 2017年剖秆 结果中钻蛙类害虫的发生频率相较于 2015年有一 定程度的提高，但没有直接证据显示是其对 $B t$ 蛋白 的抗性水平提高导致的，与调查的偶然性以及 $B t$ 蛋 白在不同年份间表达量的差异均有关系，还需要进 一步验证。(3)农药施用减少后次要害虫的暴发。研 究表明Bt抗虫棉(Lu et al, 2010)虽然控制了棉铃虫 危害, 但是由于棉田的低农药状态，一些次要害虫 如绿盲蝽(Apolygus lucorum)的危害加重甚至发展 为棉田主要害虫。在本次试验中, 两年田间主要害 虫分别为双斑长跗萤叶甲和玉米蚜, 并未在转基因 与非转基因材料上表现出差异, 且未观察到明显的 次要害虫上升问题。

\section{4 结论与展望}

综上所述，尽管转基因玉米田与对照田间部分 节肢动物的数量存在一定的差异，但两年的调查结 果显示本研究 ‘DBN9936”、'DBN318’、“先玉335’ 和‘DBN9936’喷除草剂种植区中节肢动物累计数量 的功能团组成及其丰富度、多样性、均匀度、优势 
集中性间均无明显的差异，群落间相似性程度较高， 不同处理玉米田的丰富度指数、多样性指数、均匀 度指数、优势集中性指数和群落相似性指数随时间 变化的动态趋于一致, 在部分时间点多样性指数的 变化可结合当时气候、温度、优势物种等做出解释。 由此可见, 在本次研究中, 转基因玉米“DBN9936” 的种植对田间节肢动物群落的功能团组成基本无 明显的负效应, 对田间节肢动物的多样性没有明显 的影响。

近年来国内外在转基因作物的安全性研究方 面已经取得很大进展, 对于转基因玉米农田生态系 统中节肢动物群落多样性的影响, 大部分研究证明 转基因作物对节肢动物群落多样性不会产生明显 的影响(Naranjo et al, 2005; Marvier et al, 2007; 郭 佳惠等, 2016; Farinos et al, 2018; 何浩鹏等, 2018), 也有些研究证明抗虫转基因作物的种植减少了杀 虫剂的使用, 从而提高了田间节肢动物群落的丰富 度和多样性, 进而提高了大田系统的生态稳定性 (Bhatti et al, 2005; Bitzer et al, 2005), 还有研究证明 转基因抗虫作物会造成非靶标害虫数量的上升和 天敌昆虫数量的下降(Hilbeck et al, 1998; 李保平等, 2002; 刘清松等, 2014)。由此可见, 转基因作物是否 会对非靶标生物产生影响依旧存在争议。本研究虽 然可以得到转基因玉米'DBN9936'对非靶标节肢动 物的数量和群落结构没有明显负面影响的结论, 但 大田生物安全评价是一个长期研究的过程, 需要在 多个地点进行多次多年的检测以丰富重复试验结 果, 从而得到更为全面可靠的结论。此外, 通过食 物链的传递, 很多能量和毒素等都会随之累积, 因 而对非靶标节肢动物的影响也可能会通过植物一害 虫-天敌的食物链进行传递。未来可结合生理和毒 理的实验, 研究转基因作物对靶标昆虫生理代谢的 影响(李丽莉等, 2004; 杨艳等, 2014), 也可研究转 基因作物对靶标昆虫转录组、蛋白组和代谢组的影 响, 从更多方面验证试验结果是否全面可靠, 以更 好地对转基因作物进行安全监测, 从而为人们的生 产生活提供更加科学和安全的建议。

致谢: 感谢北京大北农生物技术有限公司提供试验 材料和研究场地，感谢焦国伟、牛宏波、司东阁等 在节肢动物识别和记录上给予的帮助。

\section{参考文献}

Arias-Martín M, García M, Castañera P, Ortego F, Farinós GP (2016) Farm-scale evaluation of the impact of Cry1Ab Bt maize on canopy nontarget arthropods: A 3-year study. Insect Science, 25, 87-98.

Bhatti MA, Duan J, Head GP, Jiang CJ, Mckee MJ, Nickson TE, Pilcher CL, Pilcher CD (2005) Field evaluation of the impact of corn rootworm (Coleoptera: Chrysomelidae)-protected Bt corn on foliage-dwelling arthropods. Environmental Entomology, 34, 1336-1345.

Bitzer RJ, Rice ME, Pilcher CD, Pilcher CL, Lam WF (2005) Biodiversity and community structure of epedaphic and euedaphic springtails (Collembola) in transgenic rootworm Bt corn. Environmental Entomology, 34, 1346-1376.

Cai BH (2015) Insect Taxonomy. Chemical Industry Press, Beijing. (in Chinese) [蔡邦华 (2015) 昆虫分类学. 化学工 业出版社, 北京.]

Carrière Y, Williams JL, Crowder DW, Tabashnik BE (2018) Genotype-specific fitness cost of resistance to $B t$ toxin Cry1Ac in pink bollworm. Pest Management Science, 74, 2496-2503.

Farinos GP, Mdela P, Hernándezcrespo P, Ortego F, Castanera P (2008) Diversity and seasonal phenology of aboveground arthropods in conventional and transgenic maize crops in central Spain. Biological Control, 44, 362-371.

Guo JF, He KL, Hellmich RL, Bai SX, Zhang TT, Liu YJ, Ahmed T, Wang ZY (2016) Field trials to evaluate the effects of transgenic Cry1Ie maize on the community characteristics of arthropod natural enemies. Scientific Reports, 6, 22102.

Guo JH, Ji GZ, Li G, Zhao JN, Yang DL, Zhang GL, Yan FM, Xiu WM (2016) The impact of non-Bt genetically modified cotton on the community diversity and food-web structure of arthropods. Cotton Science, 28, 81-86. (in Chinese with English abstract) [郭佳惠, 冀国桢, 李刚, 赵建宁, 杨殿 林, 张贵龙, 间凤鸣, 修伟明 (2016) 3种转非抗虫基因棉 花田间节肢动物群落的多样性和食物网结构. 棉花学报, 28, 81-86.]

Guo JY, Zhou HX, Wan FH, Han ZJ (2007) Structure and seasonal dynamics of arthropods in transgenic cotton fields. Acta Agriculturae Boreali-Sinica, 22(6), 183-189. (in Chinese with English abstract) [郭建英, 周洪旭, 万方浩, 韩召军 (2007) 转基因棉田节肢动物群落结构与动态. 华北农学报, 22(6), 183-189.]

He HP, Ren ZT, Shen WJ, Liu B, Xue K (2018) Effects of transgenic herbicide-tolerate maize on biodiversity of arthropod communities in the fields. Journal of Ecology and Rural Environment, 34, 333-341. (in Chinese with English abstract) [何浩鹏, 任振涛, 沈文静, 刘标, 薛壁 (2018) 耐除草剂转基因玉米对田间节肢动物群落多样性的影响. 生态与农村环境学报, 34, 333-341.]

Hilbeck A, Baumgartner M, Fried PM, Bigler F (1998) Effects 
of transgenic Bacillus thuringiensis corn-fed prey on mortality and development time of immature Chrysoperla carnea (Neuroptera: Chrysopidae). Environmental Entomology, 27, 480-487.

International Service for the Acquisition of Agri-biotech Applications (ISAAA) (2017) Global biotechnology / GM crop commercial development trend in 2016. China Biotechnology, 37(4), 1-8. (in Chinese) [国际农业生物技 术应用服务组织 (2017) 2016年全球生物技术/转基因作 物商业化发展态势. 中国生物工程杂志, 37(4), 1-8.]

Kang L, Chen M (2013) GMO biosafety management, suggestions and biotech public acceptance in China. Plant Physiology Journal, 49, 637-644. (in Chinese with English abstract) [康乐, 陈明 (2013) 我国转基因作物安全管理 体系介绍、发展建议及生物技术與论导向. 植物生理学 报, 49, 637-644.]

Li BP, Meng L, Wan FH (2002) The impact of insect resistant transgenic crops on natural enemies. Chinese Journal of Biological Control, 18, 97-105. (in Chinese with English abstract) [李保平, 孟玲, 万方浩 (2002) 转基因抗虫植物 对天敌昆虫的影响. 中国生物防治学报, 18, 97-105.]

Li F, Sun HW, Zhao W, Yang SK, Lu XB (2013) Effects of herbicide-tolerant transgenic soybean on biodiversity of arthropod community in field. Shandong Agricultural Sciences, 45(7), 83-86. (in Chinese with English abstract) [李 凡, 孙红炜, 赵维, 杨淑珂, 路兴波 (2013) 抗除草剂转 基因大豆对田间节肢动物群落多样性的影响. 山东农业 科学, 45(7), 83-86.]

Li LL, Wang ZY, He KL, Peng YF, Hua L (2004) Impact of the insect-resistant transgenic crops on non-target insects. Acta Ecologica Sinica, 24, 1793-1802. (in Chinese with English abstract) [李丽莉, 王振营, 何康来, 彭于发, 花蕾 (2004) 转基因抗虫作物对非靶标昆虫的影响. 生态学报, 24, 1793-1802.]

Li Q (2011) Species accumulation curves and its application. Chinese Journal of Applied Entomology, 48, 1882-1888. (in Chinese with English abstract) [李巧 (2011) 物种累积曲 线及其应用. 应用昆虫学报, 48, 1882-1888.]

Li YH, Zhang XJ, Chen XP, Romeis J, Yin XM, Peng YF (2015) Consumption of Bt rice pollen containing Cry1C or Cry2A does not pose a risk to Propylea japonica (Thunberg) (Coleoptera: Coccinellidae). Scientific Reports, 5, 7679.

Liu QS, Li YH, Chen XP, Peng YF (2014) Research progress in chemical communication among insect-resistant genetically modified plants, insect pests and natural enemies. Chinese Journal of Applied Ecology, 25, 2431-2439. (in Chinese with English abstract) [刘清松, 李云河, 陈秀萍, 彭于发 (2014) 转基因抗虫植物-植食性昆虫-天敌间化 学通讯的研究进展. 应用生态学报, 25, 2431-2439.]

Lu YH, Wu KM, Jiang YY, Xia B, Li P, Feng HQ, Kris AG, Guo YY (2010) Mirid bug outbreaks in multiple crops correlated with wide-scale adoption of $B t$ cotton in China. Science, 328, 1151-1154.
Magurran AE (2013) Measuring Biological Diversity. Blackwell Publishing, Oxford.

Marques LH, Santos AC, Castro BA, Storer NP, Babcock JM, Lepping MD, Fernandes OA (2018) Impact of transgenic soybean expressing Cry1Ac and Cry1F proteins on the non-target arthropod community associated with soybean in Brazil. PLoS ONE, 13, e0191567.

Marvier M, Mccreedy C, Regetz J, Kareiva P (2007) A meta-analysis of effects of $B t$ cotton and maize on nontarget invertebrates. Science, 316, 1475-1477.

Naranjo SE, Head G, Dively GP (2005) Field studies assessing arthropod nontarget effects in Bt transgenic crops: Introduction. Environmental Entomology, 34, 1178-1180.

Ren ZT, Shen WJ, Liu B, Xue K (2017) Effects of transgenic maize on biodiversity of arthropod communities in the fields. Scientia Agricultura Sinica, 50, 2315-2325. (in Chinese with English abstract) [任振涛, 沈文静, 刘标, 薛 壁 (2017) 转基因玉米对田间节肢动物群落多样性的影 响. 中国农业科学, 50, 2315-2325.]

Shen P, Zhang QY, Lin YH, Li WL, Li A, Song GW (2016) Thinking to promote the industrialization of genetically modified corn of our country. China Biotechnology, 36(4), 24-29. (in Chinese with English abstract) [沈平, 章秋艳, 林友华, 李文龙, 李昂, 宋贵文 (2016) 推进我国转基因 玉米产业化的思考. 中国生物工程杂志, 36(4), 24-29.]

Shetty MJ, Chandan K, Krishna HC, Aparna GS (2018) Genetically modified crops: An overview. Journal of Pharmacognosy and Phytochemistry, 7, 2405-2410.

Skoková HO, Svobodová Z, Spitzer L, Doležal P, Hussein HM, Sehnal F (2015) Communities of ground-dwelling arthropods in conventional and transgenic maize: Background data for the post-market environmental monitoring. Journal of Applied Entomology, 139, 31-45.

Storer NP, Babcock JM, Schlenz M, Meade T, Huckaba RM (2010) Discovery and characterization of field resistance to Bt maize: Spodoptera frugiperda (Lepidoptera: Noctuidae) in Puerto Rico. Journal of Economic Entomology, 103, 1031-1038.

Tabashnik BE, Gassmann AJ, Crowder DW, Carrière Y (2008) Insect resistance to $B t$ crops: Evidence versus theory. Nature Biotechnology, 26, 199-202.

Wu L, Zhao QZ, Li DQ, Wang JR, Liu MF, Yang ZL (2016) Application of species accumulation curves in study on fruit flies in Nanting River basin. China Plant Protection, 36(8), 46-49. (in Chinese with English abstract) [吴岚, 赵琴植, 李德强, 汪金容, 刘梅芳, 杨子林 (2016) 物种累积曲线 在南汀河流域实蝇调查研究中的应用. 中国植保导刊, 36(8), 46-49.]

Xue K, Zhang WG (2008) Non-target effects of transgenic plant: Transgenic Bt cotton. Journal of the Central University of Nationalities (Natural Sciences Edition), 17(Suppl.), 40-50. (in Chinese with English abstract) [薛壁, 张文国 (2008) 转基因植物的非靶标效应一以转 $B t$ 基因棉为例. 
中央民族大学学报(自然科学版), 17(Suppl.), 40-50.]

Yang Y, Li YH, Cao FQ, Cheng LS, Peng YF (2014) Progress in the assessment of ecological effects of insect-resistant $B t$ crops on non-target of Lepidopteran insects. Journal of Biosafety, 23, 224-237. (in Chinese with English abstract) [杨艳, 李云河, 曹凤勤, 程立生, 彭于发 (2014) 转Bt 基 因抗虫作物对鳞翅目非靶标昆虫生态影响的研究进展. 生物安全学报, 23, 224-237.]

Yin JQ, Wu FC, Zhou L, Song XY (2017) Impacts of a transgenic insect-resistant maize (Bt-799) containing a Cry1Ac gene on arthropod biodiversity. Journal of Biosafety, 26, 159-167. (in Chinese with English abstract) [尹俊 琦, 武奉慈, 周琳, 宋新元 (2017) 转Cry1Ac基因抗虫玉 米Bt-799对田间节肢动物群落多样性的影响. 生物安全 学报, 26, 159-167.]

Zhang XJ, Li YH, Romeis J, Yin XM, Wu KM, Peng YF
(2014) Use of a pollen-based diet to expose the ladybird beetle Propylea japonica to insecticidal proteins. PLoS ONE, 9, e85395.

Zhu Y, Jiang T, Yang YZ (2017) Research advances in arthropod community in corn fields. Plant Protection, 43(6), 1-5. (in Chinese with English abstract) [朱芗, 姜蹈, 杨益众 (2017) 玉米田节肢动物群落研究进展. 植物保护, 43(6), 1-5.]

Zou Y, Sang WG, Wang SZ, Thomas EW, Liu YH, Yu ZR, Wang CL, Axmacher JC (2015) Diversity patterns of ground beetles and understory vegetation in mature, secondary, and plantation forest regions of temperate northern China. Ecology \& Evolution, 5, 531-542.

(责任编委: 戈峰 责任编辑: 间文杰)

\section{附录 Supplementary Material}

附录1 玉米田间节肢动物群落的目、科分布

Appendix 1 The order and family distribution of arthropod communities in maize fields http://www.biodiversity-science.net/fileup/PDF/2018316-1.pdf 
马燕婕, 何浩鹏, 沈文静, 刘标, 薛壁. 转基因玉米对田间节肢动物群落多样性的影响. 生物多样性, 2019, 27 (4): 419-432. http://www.biodiversity-science.net/CN/10.17520/biods.2018316

附录1 玉米田间节肢动物群落的目、科分布

Appendix 1 The order and family distribution of arthropod communities in maize fields

\begin{tabular}{|c|c|c|}
\hline 纲 Class & 目 Order & 科 Family \\
\hline \multirow[t]{14}{*}{ 昆虫纲 Insecta } & 弹尾目 Collembola & 圆䖴科 Sminthuridae; 长角䖴科 Entomobryidae \\
\hline & 蜻蜓目 Odonata & 蜻科 Libellulidae; 蟌科 Coenagrionidae \\
\hline & 螳螂目 Mantedea & 螳螂科 Mantidae \\
\hline & 直翅目 Orthoptera & $\begin{array}{l}\text { 斑腿蝗科 Catantopidae; 蚉斯科 Tettigoniidae; 菱蝗科 Tetrigidae; 蚤蝼科 Tridactylidae; } \\
\text { 蝼蟀科 Gryllidae }\end{array}$ \\
\hline & 革翅目 Dermaptera & 蠸螋科 Forficulidae; 蝼蛄科 Grylloidea \\
\hline & 同翅目 Homoptera & 蚜科 Aphididae; 飞虫科 Delphacida; 叶蝉科 Cicadellidae; 沫蝉科 Cercopidae \\
\hline & 半翅目 Hemiptera & $\begin{array}{l}\text { 蝽科 Pentatomidae; 长蝽科 Lygaeidae; 花蝽科 Anthocoridae; 盲蝽科 Miridae; } \\
\text { 猎蝽科 Reduviidae }\end{array}$ \\
\hline & 啮虫目 Corrodentia & 啮虫科 Psocidae \\
\hline & 缨翅目 Thysanoptera & 蓟马科 Thripidae \\
\hline & 鞘翅目 Coleoptera & $\begin{array}{l}\text { 丽金龟科 Rutelidae; 吒头甲科 Elateridae; 隐翅甲科 Staphylinidae; 蚁形甲科 Anthicidae; } \\
\text { 象甲科 Curculionoidae; 金龟科 Scarabaeidae; 䅇虫科 Coccinellidae; 天牛科 Cerambycidae; } \\
\text { 虎甲科 Cicindelidae; 露尾甲科 Nitidulidae; 䒕菁科 Meloidae; 叶甲科 Chrysomelidae; } \\
\text { 步甲科 Carabidae; 拟步甲科 Tenebrionidae }\end{array}$ \\
\hline & 脉翅目 Neuroptera & 草蛉科 Chrysopidae \\
\hline & 鳞翅目 Lepidoptera & $\begin{array}{l}\text { 夜蛾科 Noctuidae; 蛽蛾科 Pyralidae; 刺蛾科 Limacodidae; 毒蛾科 Lymantriidae; } \\
\text { 灯蛾科 Arctiidae; 枯叶蛾科 Lasiocampidae; 虫蛾科 Bombucidae }\end{array}$ \\
\hline & 双翅目 Diptera & 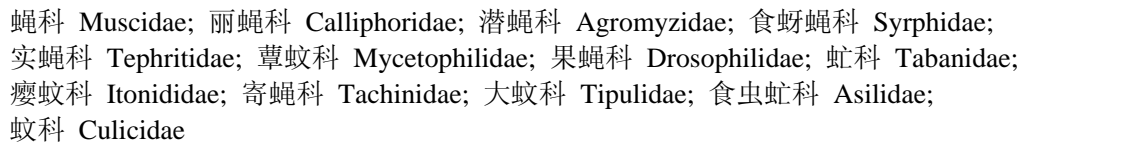 \\
\hline & 膜翅目 Hymenoptera & $\begin{array}{l}\text { 蜜蜂科 Apidae; 树蜂科 Siricidae; 赤眼蜂科 Trichogrammatidae; 胡蜂科 Vespidae; } \\
\text { 土蜂科 Scoliidae; 茧蜂科 Braconidae; 蚁科 Formicidae; 肿腿蜂科 Bethylidae }\end{array}$ \\
\hline \multirow[t]{2}{*}{ 蛛形纲 Arachnida } & 蜘蛛目 Araneida & $\begin{array}{l}\text { 园蛛科 Araneidae; 球蛛科 Theridiidae; 狼蛛科 Lycosodae; 姬蛛科 Theridiidae; } \\
\text { 跳蛛科 Salticidae; 皿网蛛科 Linyphiidae; 蟹蛛科 Thomisidae; 漏斗蛛科 Agelenidae; } \\
\text { 幽灵蛛科 Pholcidae }\end{array}$ \\
\hline & 真螨目 Acariformes & 叶螨科 Tetranychidae \\
\hline \multirow[t]{2}{*}{ 唇足纲 Chilopoda } & 蜈蚣目 Scolopendromorpha & 蜈蚣科 Scolopendridae \\
\hline & 蚰蜒目 Scutigeromorpha & 蚰蜒科 Scutigeridae \\
\hline \multirow[t]{2}{*}{ 倍足纲 Diplopoda } & 山蜰目 Spirobolida & 山望科 Spirobolidae \\
\hline & 带马陆目 Polydesmida & 条马陆科 Paradoxosomatidae \\
\hline
\end{tabular}

